\title{
A Decisão de uma Mulher por Parir Naturalmente: Contribuições Psicanalíticas ${ }^{1}$
}

\author{
Flávia Angelo Verceze ${ }^{2}$ \\ ${ }^{2}$ Universidade Estadual de Londrina, PR, Brasil.
}

\author{
Silvia Nogueira Cordeiro ${ }^{2}$ \\ ${ }^{2}$ Universidade Estadual de Londrina, PR, Brasil.
}

Resumo: Pensando a decisão como um processo que depende muito menos do pensamento racional, como se costuma acreditar, posto que nele está implicada uma lógica subjetiva de cada sujeito, este estudo teve como objetivo identificar os motivos que subjazem à decisão de uma mulher por um parto natural, em um contexto social que ainda tem como modelo hegemônico o parto medicalizado e predominantemente hospitalar. Tratou-se de uma pesquisa clínicoqualitativa, em que foram realizadas entrevistas semidirigidas com dez mulheres que passaram pela experiência de um parto natural, que foram selecionadas pela técnica de amostragem por bola de neve. A interpretação dos resultados foi realizada segundo a técnica de análise temática de conteúdo por meio do aporte teórico da psicanálise. Foi possível concluir que a decisão de uma mulher por uma ou outra via de parto tem relação com seu processo de constituição enquanto mulher e mãe, que se encontra estreitamente vinculado à relação mãe e filha. Em outras palavras, a decisão por uma ou outra via de parto está para além de um pensamento racional e uma lógica consciente, pois tem relação com os traços de experiências primitivas de cada sujeito. Além disso, pode-se perceber o quanto a decisão por um parto natural aparentou se configurar como uma tentativa de singularização da mulher, isto é, tal decisão traz a marca de uma inventividade. Essas mulheres, ao decidirem por um parto natural, apresentavam como demanda uma nova forma de parir - parir à sua maneira.

Palavras-chave: Parto Natural, Decisão, Relação Mãe e Filha, Psicanálise.

\section{A Woman's Decision to Have a Natural Childbirth: Psychoanalytic Contributions}

\begin{abstract}
From a conception of decision as a process that depends less on rationality than usually thought, for it implies each person's subjective thinking, this study aimed to identify the reasons underlying a woman's decision for having a natural childbirth, in a social context where the hegemonic model is a medicalized delivery within the hospital setting. This clinical-qualitative research was conducted with data collected using semi-structured interviews with ten women who had a natural childbirth, selected by snowball sampling. Results were interpreted in the light of thematic analysis with the theoretical contribution of psychoanalysis. A woman's decision for a different birth method was found to be related to the construction of her identity as both a woman and a mother, which is directly associated with the mother-daughter relationship. In other words, such a decision is beyond rational sense and conscious logic, being related to each subject's primitive experiences. Moreover, the decision for a natural childbirth represents an attempt for women's singularization, thus reflecting some inventiveness. When opting for a natural birth, these women demanded for a new way of giving birth - giving birth in their own way.
\end{abstract}

Keywords: Natural Childbirth, Decision, Mother-Daughter, Psychoanalysis.

${ }^{1}$ Artigo extraído da dissertação de mestrado em Psicologia da autora Flávia Angelo Verceze, intitulada "A decisão pelo parto natural e sua relação com a sexualidade feminina" (2019). 


\title{
La Decisión de una Mujer por el Parto Natural: Aportes Psicoanalíticos
}

\begin{abstract}
Resumen: Considerando la decisión como un proceso que depende menos del pensamiento racional como se cree, lo que implica una lógica subjetiva de cada sujeto, este estudio tuvo por objetivo identificar las razones que subyacen en la decisión de una mujer por el parto natural en un contexto social que todavía sigue el modelo hegemónico del parto médico y hospitalario. Esta es una investigación clínico-cualitativa, en la que se realizaron entrevistas semidirigidas con diez mujeres que se sometieron a la experiencia del parto natural, seleccionadas bajo la técnica de muestreo de bola de nieve. La interpretación de los resultados se realizó con la técnica de análisis de contenido temático mediante la contribución teórica del psicoanálisis. Se concluye que la decisión de una mujer por una u otra forma de parto está relacionada con su proceso de constitución como mujer y madre, que está estrechamente vinculada a la relación madre e hija. Es decir, la decisión por un u otro tipo de parto va más allá de un pensamiento racional y una lógica consciente, pero está relacionada con los rasgos de las experiencias primitivas de cada sujeto. Además, se observó cómo la decisión por un parto natural parece ser un intento de singularización de la mujer, es decir, esta decisión lleva la marca de una inventiva. Estas mujeres al decidirse por el parto natural presentaron como demanda una nueva forma de parir: parir a su manera.
\end{abstract}

Palabras clave: Parto Natural, Decisión, Relación Madre-Hija, Psicoanálisis.

\section{Introdução}

O parto se caracteriza como um fenômeno humano, biológico e simbólico que passou por muitas transformações no decorrer da História. Se na antiguidade até a Idade Média ele acontecia quase que estritamente no ambiente domiciliar com o acompanhamento de parteiras, cujos conhecimentos eram passados de geração em geração e eram predominantemente míticos e cerimoniais, com a entrada do saber médico, o fenômeno do parto se transforma. Segundo Vieira (2002), embora a aproximação dos médicos ao parto data de um período anterior, só durante os séculos XVIII e XIX que as práticas dos cuidados com o corpo feminino são consideradas como competência exclusiva dos médicos, o que se desenvolve e se legitima ao longo dos séculos.

De acordo Martins (2004), o corpo, a sexualidade e a reprodução se tornaram objetos privilegiados do discurso científico da modernidade que começa a se materializar, marcando o início da constituição da ginecologia e da obstetrícia como especialidades médicas. Neste contexto, ocorre a medicalização do parto, que se configurou como um processo longo, visto que começou por volta de trezentos anos antes da institucionalização e do estabelecimento dessa área do conhecimento como área médica. $\mathrm{O}$ parto foi arrancado da casa, da intimidade, e levado para os hospitais, passando a ser realizado por especialistas, tornando-se asséptico, limpo, higiênico e predominantemente hospitalar (Vieira, 2002).

De acordo com Davis-Floyd (1992), esse modelo de atendimento ao parto, chamado de tecnocrático, tem como princípio a padronização e a tecnificação dos cuidados, o que leva ao apagamento das singularidades das parturientes, transmitindo uma cultura e uma ordem simbólica globalizada, guiada pela ciência, pela tecnologia, pelo lucro e pelo controle institucional dos corpos femininos. Nesse contexto, o distanciamento entre o parto e a sexualidade feminina é aceito, proposto e, muitas vezes, até mesmo imposto em casos de substituição do ato de parir pela cirurgia cesariana, o que reforça a dependência da mulher em relação à ciência e à institucionalização (Borges, 2015).

O modelo tecnocrático ainda é hegemônico na maioria dos países, inclusive no Brasil, e tem como consequência práticas intervencionistas com ênfase em resultados a curto prazo e não necessariamente embasadas em evidências científicas. De acordo com Santos (2002), a medicina em geral e, em particular, a obstetrícia, são baseadas não somente nessa ideologia tecnocrática, mas também na ideologia de uma sociedade patriarcal. Assim, nesse modelo tecnocrático, a gravidez, o parto e o nascimento são entendidos 
por uma perspectiva industrializada, tecnológica e sob ótica masculina, tornando a parturiente um objeto em que alguns procedimentos e rotinas deverão ser realizados em todos os partos.

Todavia, entre as décadas de 1970 e 1980, iniciaram-se debates em torno da medicalização do parto. Essa crítica se dá a partir da ideia de que o parto não é um evento patológico, mas sim existencial e social vinculado à sexualidade da mulher. Inicia-se, assim, um novo ideário do parto, intitulado como Humanização do Parto. O parto humanizado se constitui por um conjunto de valores e propostas partilhados por pessoas que recusam formas altamente medicalizadas para o nascimento de seus filhos e que, embora recuperem inúmeros elementos de um tempo passado, não seguem a forma tradicional, configurando a humanização como uma reinvenção da tradição (Tornquist, 2002).

Dessa forma, a escolha por um parto natural traz a decisão como um fator importante de análise, pois, embora o parto natural pareça retornar os partos feitos em casa antes do surgimento da medicina moderna, distancia-se deles na medida em que antes inexistia opção, as mulheres tinham partos normais em casa porque não existia o parto hospitalar. Nesse sentido, faz-se importante compreender como se configura um processo de decisão.

\section{A decisão sob a ótica da psicanálise}

Na psicanálise não há explicitamente uma teoria sobre os processos de decisão. A palavra decisão aparece em alguns momentos da obra freudiana, mas sem valor conceitual. Todavia, Freud (ca. 1900/1972; 1901/1996), ao apresentar a causalidade psíquica inconsciente, revela o quão pouco a decisão depende do pensamento racional, ao sustentar uma forte aposta no determinismo inconsciente como regente da vida anímica . A decisão é pensada como um ato e, assim, implica um posicionamento subjetivo singular, não podendo ser explicada como um resultado de um pensamento racional produzido por dados de realidade concretos. A apreensão da realidade pode percorrer caminhos inusitados, nem sempre traçados por uma lógica da razão e da consciência; há algo no processo que escapa a lógica da racionalidade.

Freud (ca. 1900/1972) demonstrou, em "A interpretação dos sonhos", que existe uma lógica diferente da lógica consciente e racional que opera na apreensão da realidade, não sendo, portanto, destituída de sentido. Assim, como os sonhos escapam de toda lógica da consciência e se organizam para circunscrever um sentido particular da realidade psíquica, os atos do sujeito também preservam algo que não é da ordem da intencionalidade do eu, mas que opera em suas manifestações. Lacan (1953/2008) afirma que o modo particular pelo qual a realidade se apresenta ao sujeito é marcada por uma estrutura mítica, isto é, construções imaginárias que operam para que um sujeito possa dar conta de determinada verdade subjetiva. Com isso, muitas vezes nos processos de decisão está implicada uma lógica subjetiva que nem sempre condiz com os supostos fatores externos que levariam a uma ou outra decisão.

Assim, essa outra lógica que orienta os processos de pensamento e é diferente daquelas que orientam o raciocínio e a ação controlada, se é que isso é viável, tem relação com os traços de experiências primitivas de cada sujeito. Portanto, percebe-se que os processos de decisão estão vinculados à história de cada indivíduo e à maneira como suas primeiras relações se deram. No que concerne ao feminino, a figura materna tem destaque devido não somente a sua função estruturante, presente em ambos os sexos, mas também pela estranha consistência do vínculo que une uma filha à sua mãe. Portanto, faz-se importante compreender do que se tratam esses processos iniciais e sua especificidade na mulher.

\section{A relação mãe e filha e os percalços na construção da maternidade}

Freud (1924/1996) coloca Édipo, herói da mitologia grega, como fenômeno fundamental no desenvolvimento da sexualidade e traz como ponto crucial para a estruturação sexual de ambos os sexos a primazia fálica. No caso da menina, a primazia só funciona como organizadora, visto que será pelo desejo de ter um falo que se processará o acesso à feminilidade. Todavia, isso só acontece se o desejo de ter um falo for substituído pelo desejo de ter um filho de seu pai, o que marca o início do Complexo de Édipo na menina. Assim, para Freud, o acesso à feminilidade está ligado ao afastamento da filha em relação à mãe, por não ter lhe fornecido o pênis, o que leva a filha em direção ao pai. Neste sentido, é possível perceber a insistência de Freud de retornar à questão da reprodução e da diferença anatômica como estruturação sexual em ambos os sexos. Ademais, ainda sustenta a teoria da inveja do pênis para explicar a constituição da feminilidade. Com isso, podemos dizer que a 
teoria sobre a sexualidade feminina de Freud é muito apegada às questões da família tradicional burguesa de sua época, que via as mulheres atreladas ao papel de dona de casa e mãe.

Todavia, quando Freud postula a questão "o que quer a mulher?", começa a constatar que cabe à menina, para se tornar mulher, um encargo trabalhoso e contínuo. Mais do que ser, a feminilidade é tornar-se. Assim, a transformação da menina em mulher ocorre, sobretudo, pelo afastamento da mãe, tarefa que não se mostrará fácil (Zalcberg, 2003).

Dessa maneira, segundo Zalcberg (2003), Freud focalizará a maioria de seus estudos posteriores na sexualidade feminina e na importância que a relação pré-edípica tem no destino da mulher. Entretanto, Freud não conseguiu responder ao seu próprio questionamento, apontando o feminino como um enigma. Mas, ele deixa uma pista ao dizer que o Complexo de Édipo não dá conta do feminino, destacando a relação pré-edípica como essencial para desvendar o enigma do feminino.

O que é realizado posteriormente por Lacan é um retorno aos textos freudianos e seus princípios para avançar na teoria psicanalítica, sem, portanto, descartar as contribuições de Freud. Assim, pode-se observar que Lacan não recusa a teoria da primazia fálica, mas extrai dela suas implicações para homens e mulheres. Segundo Zalcberg (2003), Lacan tratará de reconhecer que as mulheres não se submetem totalmente à ordem fálica e indica uma forma de sair do impasse causado pela formulação de Freud da inveja da mulher do pênis. Isto é, para Lacan, não se trata propriamente da falta de um órgão, mas sim da falta de um símbolo específico da sexualidade feminina, como o falo é para o homem.

Em "Seminário, livro 18: de um discurso que não fosse semblante", Lacan (1971/2009) postula sua controversa frase: "A mulher não existe" (p. 69), ou seja, para Lacan, por não haver um significante que represente o sexo feminino, não existe A mulher, universal e transcendente ao conjunto de todas as mulheres. Ela só existe em sua singularidade, isto é, não existe a mulher enquanto representação do que é ser mulher. Dessa maneira, a mulher não possui um traço identificatório em que possa apoiar sua posição feminina, o que faz com que cada mulher busque em sua semelhante um traço de feminilidade que lhe falta, a começar pela mãe. E, por essa condição, a cada mulher é imposta a tarefa de criar a sua maneira de ser, uma vez que é não toda fálica.
Neste sentido, pode-se concluir que a teoria psicanalítica lacaniana avança quanto ao entendimento do feminino, pois, segundo ela, há no feminino algo que não pode ser universal e representável, não podendo mais ser explicado segundo uma concepção naturalística baseada no corpo biológico da mulher e em sua capacidade de concepção e gestação. $O$ padrão de feminilidade se transformou, abrindo caminhos para novas formas de sexuação na mulher.

Diante disso, não se deve ignorar que alguém se torna mulher ou mãe no interior dos mitos criados pelo imaginário social e cultural. Esses "mitos" agem como organizadores do sentido do agir, do pensar e do sentir dos indivíduos. São narrativas que se repetem nos discursos médico, religioso, jurídico, midiático e até mesmo dentro da psicologia, estabelecendo uma valoração e uma desvaloração. Criam-se, assim, subjetividades (Alonso, 2015).

Em relação à mulher, um mito que se destaca é o mito da mulher mãe que passa a imperar no imaginário social da modernidade. Segundo Fernández (1994, p. 161), inverte-se a situação do "para ser mãe é preciso ser mulher, para ser mulher é preciso ser mãe", isto é, coloca-se o feminino no materno, excluindo todo o resto da mulher. Ainda segundo a autora, outro mito que aparece conjuntamente com este é o da "maternidade feliz", que enfatiza a maternidade como o momento de maior plenitude da vida de uma mulher. Segundo Alonso (2015), neste último mito se produz um corte recalcante dos processos ambivalentes que estão presentes na maternidade, levando a uma santificação da maternidade, que passa a ser radicalmente separada da sexualidade.

De acordo com Alonso (2015), esses mitos são criações culturais de um determinado momento histórico que se apresentam ao social através de uma ilusão de naturalidade e atemporalidade, como é o caso do instinto materno. Entretanto, todos os atos humanos estão inscritos na cultura, pois "não há materialidade da carne que não esteja atravessada pela linguagem" (Alonso, 2015, p. 342).

Neste sentido, a psicanálise pode ampliar a discussão a respeito do processo de decisão por um parto natural ao apontar que há outra lógica que orienta os processos de pensamento. Assim, indaga-se se a decisão por um parto natural, em um contexto social que ainda tem como modelo hegemônico o parto instrumentalizado, medicalizado e predominantemente hospitalar, relaciona-se com questões subjetivas e constitutivas da mulher que escolhe parir de outra maneira, dita como natural. 


\section{Método}

Este artigo se trata de um estudo clínico-qualitativo, que consiste em um método de investigação dentro das pesquisas qualitativas, isto é, um método criado através de uma particularização e refinamento das pesquisas qualitativas genéricas. Neste tipo de pesquisa, há uma valorização de referenciais psicanalíticos para a compreensão dos fenômenos estudados, desde os aspectos psicodinâmicos no momento de contato com participantes até o referencial teórico para a discussão dos resultados, apesar de não se tratar de um método propriamente psicanalítico (Turato, 2003).

Participaram da pesquisa dez mulheres de 23 a 39 anos, em sua maioria casadas, com ensino superior e de pele branca, que passaram pela experiência de parir naturalmente - aqui entendido como parto vaginal - sem anestesia, analgésicos ou substâncias para induzir o parto. Foram excluídas da pesquisa mulheres menores de 18 anos e as que apresentaram algum transtorno psiquiátrico. As participantes foram selecionadas segundo a técnica de amostragem por bola de neve (Turato, 2003).

A primeira participante foi indicada pela orientadora do trabalho e a amostra foi fechada depois da décima entrevista, quando se percebeu que os dados obtidos passaram a apresentar certa redundância, não mais contribuindo significativamente para o aperfeiçoamento da reflexão teórica fundamentada. Além disso, a cada entrevista, foi se restringindo o número de participantes indicadas, que é característico de uma amostragem por bola de neve.

É importante ressaltar que a amostra desta pesquisa, pela própria técnica de amostragem, trata de um grupo restrito e homogêneo, formado por mulheres de classe média, em sua maioria branca e com ensino superior, que optaram por um retorno ao natural e à intimidade na vivência do parto.

As entrevistas foram semidirigidas de questões abertas onde, segundo Bleger (1998), o entrevistador tem ampla liberdade para perguntas ou intervenções, permitindo-se toda a flexibilidade necessária de cada caso. As entrevistas foram realizadas em ambientes escolhidos pelas participantes e que permitissem privacidade. Os nomes das participantes foram suprimidos e substituídos pela letra $\mathrm{M}$ (mulher) e por números na ordem que as entrevistas aconteceram.

A interpretação dos resultados foi realizada a partir da técnica de análise temática de conteúdo de Bardin (2011), que consiste em um conjunto de técnicas de análise das comunicações que utiliza procedimentos sistemáticos de descrição do conteúdo das mensagens, levando em consideração o contexto social e histórico sob os quais foram produzidas para, a partir das mensagens, criar inferências e embasá-las com pressupostos teóricos (Bardin, 2011). Tal método permitiu a criação de quatro categorias: "Por que ainda parir? A decisão pelo parto natural"; "A gestação e o parto como experiência de fazer memória”; Parindo a mulher: o parto, o feminino e o materno"; "Nossa senhora, se é assim então maravilha: o parto e sua relação com a sexualidade". Porém, neste trabalho optou-se por apresentar uma dessas categorias construídas que trata mais especificamente sobre a questão da decisão por um parto natural.

Este estudo seguiu as diretrizes e normas regulamentadoras de pesquisas envolvendo seres humanos preconizadas pela Resolução no 510 (2016) e foi aprovada pelo Comitê de Ética em Pesquisa da universidade onde foi realizada.

\section{Resultados e discussão}

\section{Por que ainda parir? A decisão pelo parto natural}

A decisão pelo parto natural envolve uma série de fatores, sejam eles de natureza psicológica, histórico-social ou cultural. Todavia, muitas vezes, na literatura, são encontradas respostas simplistas e até estigmatizantes que desconsideram a complexidade envolvida na escolha por uma ou outra via de parto. Assim, nesta categoria, discutiu-se o que subjaz à decisão de uma mulher por um parto natural em tempos em que ela tem outras opções de escolha. Em outras palavras, o contexto atual dá novas liberdades à mulher no que concerne a parturição, colocando-as numa posição nova em que o parir é uma escolha, não um destino. Assim, interroga-se se haveria algo no desejo feminino que sustente a decisão por parir naturalmente - por que ainda parir?

Pode-se observar nas falas das entrevistadas, ao serem indagadas sobre os motivos que as levaram a escolher um parto natural, uma referência à história de seus nascimentos e aos partos de suas mães:

Eu sempre quis parto normal, mesmo antes quando eu não pensava em ter filhos, eu pensava se um dia eu tiver filho eu quero que seja de parto normal, porque eu nasci de parto normal e meus irmãos não e foi uma experiência bem dificil para minha mãe... 
E foram coisas que a gente sempre conversou muito em casa, sobre nascimento, da conexão com o outro ... Então foram essas pequenas coisas que somaram e eu sempre falei que queria... Ai quando eu engravidei eu sabia o que eu queria já (M9).

Bom, eu sempre quis parto normal, porque minha mãe teve um parto normal e uma cesárea e ela tinha esse comparativo e o parto normal apesar de tudo tinha sido melhor, então na minha cabeça eu sempre quis... Eu sempre gostei muito do assunto de gestação, então já pesquisava bastante e já estava em grupo que chamava cesárea, não obrigada já fazia muito tempo ... eu já sabia o que era violência obstétrica, conversei muito com a minha mãe, vi como era naturalizado (M6).

No começo, quando eu descobri que eu tava grávida, eu tinha muito medo de anestesia porque a minha mãe teve alergia, ela teve uma cesárea e ela falou a vida inteira mal da cesárea ... No meu parto acho ela tomou anestesia geral por conta disso, não me viu nascer, a gente ficou sete horas separadas, pra ela foi um trauma (M5).

Nas falas acima podemos perceber o quanto as histórias de seus nascimentos e dos partos de suas mães ancoraram as decisões dessas mulheres por um parto natural, seja de uma maneira de continuação ou de transformação, isto é, porque a mãe teve um parto natural ou porque não o teve. Assim, pode-se interrogar se há algo como um "mandato" materno, ou seja, a assunção do desejo materno como uma vocação ou até mesmo concretização do que a mãe não foi "capaz” de fazer.

Segundo Zalcberg (2003), a relação mãe e filha não é entre uma pessoa que é mãe e outra que é filha, mas entre duas posições do sujeito mulher - no lugar de filha e no lugar de mãe, que inclui necessariamente e estruturalmente as vicissitudes da experiência de filha. Neste sentido, percebe-se que a experiência enquanto filha é de extrema importância para a constituição do ser mulher e mãe. Ainda segundo Zalcberg (2003), a história particular de cada menina com sua mãe, ao longo de sua infância e adolescência, costuma deixar nela uma indiferenciação em aspectos que tocam à sua identificação própria como mulher, que leva a uma grande dificuldade de separação da mãe, ao mesmo tempo em que sente uma necessidade de se distanciar desta.
Portanto, pode-se perceber o quanto alguns aspectos da vinculação mãe e filha, como as histórias de seus nascimentos, afetam a mulher quando ela está prestes a se tornar mãe. Freud (1931/1969) já sinalizava tal importância em seus últimos textos sobre o feminino, ao afirmar que a fase de ligação exclusiva à mãe, chamada de pré-edipiana, tem para as mulheres uma importância muito maior do que para os homens e que muitos fenômenos da vida sexual feminina, que não foram compreendidos, podem ser integralmente explicados por referências à essa fase (Freud, 1931/1969).

Segundo Alonso (2015), as memórias inscritas no corpo da filha pela relação com sua mãe se rearticulam na mulher durante sua trajetória subjetiva, que é fundamentalmente marcada pelos seus ciclos biológicos. Assim, durante momentos de transformações corporais, como a gestação e o parto, são ativadas marcas sensoriais que dão continuidade ao inacabável processo de constituição do feminino. Portanto, ao contrário do que Freud afirmava no início de sua teoria sobre o feminino, em que atribuía exclusivamente ao pai o desenvolvimento da feminilidade da filha, afirma, no final de seu percurso, que o desenvolvimento depende, sobretudo, do desdobramento da relação com a mãe. Lacan (ca. 1972/1982) posteriormente desenvolve isso ao dizer que "a filha espera receber, como mulher, mais substância de sua mãe do que de seu pai, ele vindo em segundo" (Lacan, ca. 1972/1982, p. 21).

Tal aspecto da vinculação mãe e filha foi observado nas falas das entrevistadas quando estas apresentaram como motivo para a escolha do parto natural as histórias de seus nascimentos ou as histórias de parto de suas mães, o que nos possibilita pensar o quanto a decisão por uma ou outra via de parto está para além do pensamento racional e de uma lógica consciente.

Também pôde ser observado, em algumas entrevistas, que o motivo da escolha por um parto natural foram as próprias concepções e estilos de vida das mulheres, que não concordavam com o modelo hegemônico de parturição e acreditavam na potência de seus corpos para parir. Essas mulheres aparentavam valorizar o conhecimento que tinham de seus próprios corpos, seus saberes, suas histórias e seus desejos, e por isso buscaram uma forma de parir que respeitasse suas singularidades:

Quando eu engravidei, até um pouquinho antes, eu percebi que aqui era muito dificil ter um parto natural hospitalar . . . Aí eu contatei a equipe de 
parto domiciliar porque eu não queria intervenções desnecessárias e eu tinha medo de começar uma intervenção e acabar indo pra outra ... e a questão do hospital, é um ambiente que sempre me deixou muito nervosa pra coisa simples... aí depois das consultas com as enfermeiras ficamos mais seguros da escolha, mas foi um medo do sistema obstétrico ... . tinha medo de começar cair em umas intervenções e acabar tendo um parto diferente do que eu esperava. No começo eu pensava "nossa, mas é normal, por que tanto medo?", mas é porque os históricos que a gente tem são partos violentos, partos que a mulher não é protagonista ... sempre soube o tipo de parto que eu queria e o que eu não queria (M6).

A primeira ideia foi o medo, eu tinha medo da cesárea, mas também tinha medo do parto normal... Mas, pra mim, o parto normal era uma coisa que... era um sentimento real dentro de mim, eu queria ter um parto normal, na minha cabeça eu não aceitava uma cesariana ... Pra mim o melhor é o natural do seu corpo e que a gente nasce para isso (M10).

Desde sempre eu queria ter parto normal, eu sou enfermeira obstétrica, então pra mim a primeira opção de escolha não tinha outra a não ser parto normal . . . aí quando eu fiquei grávida eu já tava envolvida no mundo da humanização, eu falei nossa, é isso que eu quero pro meu parto... eu quero um parto respeitoso ... eu quero ser respeitada ... eu quero que minhas decisões sejam levadas em consideração (M1).

Pode-se observar que muitas dessas mulheres já tinham entrado em contato com questões relativas à gestação e à parturição mesmo antes de engravidarem, seja por meio da família ou por fazerem parte de algum grupo de apoio ou movimento social. Portanto, são mulheres que já tinham alguma ideia do cenário de assistência ao parto no Brasil, com o qual não concordavam. Para elas, buscar um parto natural se configurava como uma resistência às práticas de assujeitamento, entendendo o parto como um fenômeno constitutivo de suas histórias. Assim, para elas, o parto parece ser não um evento médico, mas uma experiência de subjetivação.

Diante disso, faz-se importante questionar o posicionamento dessas mulheres frente à decisão de parir, pois estas quiseram outros modos ao que parece ter se tornado quase regra no modelo obstétrico brasileiro. Elas quiseram um parto "mais natural", na contramão do que a modernidade e o modelo médico preconizaram como seguro.

Segundo Mathias (2013, p. 67), para a psicanálise, a decisão é pensada como "um ato de um sujeito que interfere no rumo dos acontecimentos ou define os caminhos pelos quais uma pessoa conduzirá a vida" e, portanto, implica um posicionamento subjetivo singular, não podendo ser explicada como um resultado apenas racional produzido por dados de realidade concretos.

Neste sentido, pode-se também indagar se a decisão por um parto natural em um contexto cujo parto cesariano é hegemônico pode se configurar como uma tentativa de singularização da experiência. Melhor dizendo, se não há por trás dessa decisão um caráter de inventividade, pois o parto natural possibilitaria as mulheres a parir onde e como quisessem, livrando-se do intervencionismo e as colocando como autoras do processo.

A respeito disso, indaga-se se esse processo de singularização, por parte da mulher na decisão por um parto natural, não se articula com o caráter de inventividade e criação do processo pelo qual a feminilidade se constrói, segundo a perspectiva lacaniana. Segundo Lacan (1971/2009), sendo a mulher não toda fálica, nela não se encontra um significante que represente o sexo feminino, não existindo "A mulher" enquanto universal transcendente ao conjunto de todas as mulheres. Ela só existe em sua singularidade, isto é, não existe a mulher enquanto representação do que é ser mulher, cabendo a ela a tarefa de criar a sua maneira de ser. Assim, como no parto natural não há uma maneira de parir pré-determinada, como nos partos normais hospitalares, onde existe uma série de processos rotineiros, a mulher se encontra livre para parir gemendo, aos gritos, de pé, de quatro etc., ou seja, podendo exercer o processo de parto como inerente a sua feminilidade e sexualidade.

Com isso, vê-se hoje a escolha de um parto natural como um processo de decisão importante e criativo por parte das mulheres, pois o espaço doméstico se apresenta como possibilidade de criação e da maneira individual de cada mulher de parir.

Outro motivo encontrado nas falas das mulheres entrevistadas a respeito da decisão por um parto natural foi a tentativa de superação de experiências de parto anteriores insatisfatórias: 
Eu não queria cesárea . . e eu sofri violência obstétrica . . . então eu falei eu nunca mais quero filho na vida, não quero mais saber disso porque foi um trauma na minha vida. Ai depois passou um tempo eu comecei a falar "bom, a forma de eu me curar é trilhar um novo caminho, engravidar e aí conseguir parir a minha filha pra cicatrizar", cicatrizar não cicatriza, mas ajuda muito. Aí quando eu descobri que tava grávida fiquei com medo, mas falei "agora vou ter que fazer valer a pena e de alguma forma cicatrizar um pouquinho do que foi o primeiro momento, aí até aceitei a gravidez e falei "Não, agora dessa vez eu vou parir, eu vou parir e vai dar tudo certo" (M4).

Eu queria parir porque eu não tinha conseguido da primeira vez, eu queria parir porque eu queria sentir essa potência, eu queria parir porque queria ter a certeza que meu corpo funcionava ... da primeira vez eu não tinha consciência, eu ouvia o discurso, mas eu não tinha a consciência da violência, da segunda vez eu tinha a consciência porque eu vivi ela de várias formas e não era uma violência escancarada, era uma violência muito disfarçada numa figura de médico bonzinho (M7).

De acordo com Carneiro (2015), a busca por um parto humanizado pode se apresentar como uma resistência por parte das mulheres às práticas de assujeitamento e/ou de violência presentes no modelo de assistência ao parto no Brasil. Em seu estudo etnográfico com mulheres que buscaram um parto humanizado, a autora constatou histórias de mulheres que foram separadas de seus bebês, impedidas de amamentar e que vivenciaram a solidão e o desamparo nos hospitais, além da experiência de submissão a procedimentos invasivos feitos sem consentimento ou contra a vontade delas, que tiveram como consequência um grande sofrimento psíquico. Segundo a autora, para algumas dessas mulheres a dor decorrente de um parto mal assistido e violento serviu de impulso para que elas buscassem outro modo de parir quando viveram novas gestações.

Dessa forma, a decisão por um parto natural pode também ser vista como uma maneira de resistir à violência no parto, cada vez mais visível com o aumento de estudos sobre o tema da violência obstétrica. Esta se denomina como técnicas que medicalizam o parto, utilizando em larga escala procedimentos considerados inadequados e desnecessários que muitas vezes colocam em risco a saúde e a vida da mãe e do bebê. Além disso, muitos desses procedimentos acontecem sem o consentimento da mulher, sendo vistos como práticas padronizadas de atendimento ao parto.

Segundo Zanardo, Calderón, Nadal e Habigzang (2017), essas ações intervencionistas e, muitas vezes, desnecessárias, têm ocasionado a insatisfação das mulheres, que são relegadas a coadjuvantes nos processos de parto e nascimento. O parto passa a integrar um modelo centralizado na figura do médico, que exerce controle dos conhecimentos do corpo humano e da sexualidade, nesse caso, da mulher. Além das intervenções obstétricas desnecessárias, muitas mulheres relatam vivências de parto dolorosas, com ofensas, humilhações e expressão de preconceitos arraigados em relação à saúde e à sexualidade da mulher. Essa realidade é cotidiana e cruel e revela uma grave violação aos direitos humanos e aos direitos das mulheres.

Tais dados também foram encontrados nas falas de algumas das mulheres entrevistadas para esta pesquisa, que, por terem passado por uma experiência insatisfatória e violenta de parto, em uma segunda experiência optaram pelo parto natural como uma maneira de fugir desse cenário. Além disso, foi possível perceber que na segunda experiência de parto, dessa vez natural, o parto aparece com um significado de cura e de apropriação dos seus próprios corpos, como pode ser observado nas falas a seguir:

O primeiro eu quis, mas eu não pari, o segundo eu quis e consegui, eu pari, mas acho que um sem o outro não daria certo, o primeiro me ensinou muito, eu sabia o que tava me aguardando, eu falei "é isso que eu quero eu vou aguentar" (M4).

Quando eu engravidei do meu primeiro filho, eu desejava parir, mas eu não tinha consciência real de que meu corpo era perfeito e potente, eu tinha que o médico fazia parto normal e que eu ia conseguir porque o médico fazia parto humanizado e não porque eu podia parir e acho que esse deslocamento já ferra tudo na hora de parir... você tem que reconhecer no seu corpo, é você se apropriar de tudo que tá acontecendo no seu corpo ... é muito mais que isso: é você se abrir, se permitir e reconhecer sua potência $(\mathrm{M} 7)$.

Assim, pode-se observar que as mulheres que tinham uma experiência de parto anterior considerada 
insatisfatória ou até mesmo violenta viam a decisão pelo parto natural como uma forma de curar, cicatrizar essa experiência anterior. É possível notar nas falas que o parto anterior é considerado como um fracasso porque elas não conseguiram parir, algo que era almejado desde a primeira experiência. As mulheres colocam o parto como algo que elas precisavam vivenciar para sentir que seus corpos funcionavam, para sentir o que denominam de potência. Logo, percebe-se que o parto natural é visto como um fenômeno que possibilita a mulher experienciar o corpo de uma outra maneira, um corpo potente e capaz de parir.

Deste modo, ao analisar o universo simbólico que permeia as falas, foi possível observar a presença da ideia de natureza, que aparece no uso do termo "parto natural", demonstrando uma significação à respeito do fenômeno parto como se este estivesse ligado a uma essência ou uma natureza feminina, ou até mesmo como um processo instintivo.

Eu tinha essa convicção de que eu queria um parto natural humanizado, isso sempre . . o parto é normal do corpo, como respirar (M2).

Hoje eu sei que foi muito instintivo a procura, sabe, porque eu queria muito ser mãe, queria muito que aquilo acontecesse de um jeito de mulher. . aí eu comecei a ler sobre parto e descobri o parto humanizado antes de ficar grávida e pouco tempo depois eu engravidei e aí eu mergulhei mesmo no negócio do parto (M3).

Eu sempre tive essa ideia de que o parto normal é natural e faz parte da fisiologia da mulher e que meu corpo conseguia fazer aquilo, então, essa foi a opção desde que eu engravidei (M7).

De acordo com Tornquist (2002), é preciso ponderar acerca dos desdobramentos desse discurso a respeito da categoria de "natureza" presente no ideário da humanização do parto, na medida em que pode reproduzir categorias como as de instinto materno e de natureza feminina, ainda que ressignificadas nesse novo conceito. Ao apontar para um instinto e uma natureza, mesmo que poderosa e positiva das mulheres, pode-se construir novamente a ideia de uma essência feminina universal, colocando novamente feminilidade e maternidade como equivalentes e configurando uma nova estética do parto: uma forma mais natural de parir que se coloca como um modelo a ser seguido e nem sempre alcançado pelas mulheres.

Não se nega que, ao longo dos anos, as mulheres foram sem dúvida expropriadas dos saberes sobre seus próprios corpos, inclusive no campo da parturição, e que recuperá-los é, além de uma questão política, também um posicionamento subjetivo frente aos acontecimentos e fenômenos científicos e médicos. Nesse sentido, é preciso que se reafirme que humanizar o parto é entendê-lo como um evento simbólico, que envolve dimensões biológica, cultural e subjetiva.

Segundo Carneiro (2009), apesar de as mulheres adeptas ao parto natural reincidirem, em alguns momentos, no discurso moderno de natureza feminina - o que incorre no risco de uma essencialização da condição de mulher e da reprodução de mitos sociais a respeito da feminilidade e da maternidade - há, nessas mulheres, a dimensão da escolha; elas optam por parir de outro modo, enfrentando os riscos preconizados pelos médicos e se posicionando contra o modelo hegemônico de parturição. Tal fato nos faz pensar em outras configurações de subjetividades femininas que não mais a da modernidade, visto que a maioria das entrevistadas não pertenciam exclusivamente ao lar, pois contavam com uma vida profissional bastante ativa. Aparentam-se, assim, subjetividades femininas que buscam a sexualidade e a liberdade sexual até mesmo nos processos de parto e maternidade, cedendo à dicotomia procriação e erotização tão pregada na modernidade.

Ainda segundo a autora, o parto natural que acontece no espaço doméstico parece adquirir outra conotação. A começar, é a mulher que escolhe parir em casa, e nesta casa ela grita, geme, coordena o seu parto e, em algum sentido, resiste ao controle médico e à padronização de condutas, porque assim ela desejou. O doméstico aparece aqui como refúgio e como tempo-espaço de ação, isto é, trata-se de um doméstico criativo, que traz a possibilidade de ressignificação do espaço, do parto e da mulher.

\section{Considerações finais}

Pôde-se perceber com esta pesquisa que a decisão das mulheres entrevistadas por um parto natural foi resultado de uma série de motivações: suas histórias de vida, a tentativa de superar experiências de parto insatisfatórias, quererem fugir de intervenções 
médicas consideradas desnecessárias e até mesmo violentas e por considerarem o parto um processo ligado a uma suposta natureza feminina. Todavia, apesar de as mulheres apresentarem diversos motivos, a decisão por um parto natural em todas elas aparentou se configurar como uma tentativa de singularização, ainda que apareçam elementos reincidentes de uma ideia de essencialidade e natureza feminina. Logo, a decisão traz a marca de uma inventividade: parir à sua maneira e como deseja.
Este fato parece estar relacionado ao próprio processo de constituição do feminino e do materno, que, para a psicanálise lacaniana, tem um caráter de inventividade e criação - para cada mulher é imposta a tarefa de criar a sua maneira de ser. Neste sentido, pode-se concluir que a decisão por um parto natural, que foge à lógica hegemônica de parturição, pode se configurar como um processo de decisão importante e criativo, o que implica em um importante posicionamento subjetivo por parte da mulher.

\section{Referências}

Alonso, S. L. (2015). Interrogando o feminino. In S. L. Alonso, O tempo, a escuta, o feminino: Reflexões (pp. 298-320). Casa do Psicólogo.

Bardin, L. (2011). Análise de conteúdo. Edições 70. (Obra original publicada em 1977)

Bleger, J. (1998). Temas de psicologia: Entrevistas e grupos. Martins Fontes.

Borges, C. M. (2015, 16-18 set.). A estreita relação entre parto, sexualidade e as obras de Helen Knowles [Trabalho apresentado]. $3^{\circ}$ Seminário de História e Cultura: Gênero e Histografia.

Carneiro, R. G. (2015). Cenas de parto e políticas do corpo. Editora Fiocruz.

Carneiro, R. (2009, 12-17 jul.). Parto domiciliar: Ressignificação do doméstico e cronotopías da intimidade [Trabalho apresentado]. $15^{\circ}$ Simpósio Nacional de História.

Davis-Floyd, R. (1992). Birth as an American rite of passage. University of California Press.

Fernández, A. M. (1994). La mujer de la ilusión. Paidós.

Freud, S. (1969). Sexualidade feminina. In J. Strachey (Ed.), Edição Standart Brasileira das obras psicológicas completas de Sigmund Freud (Vol. 21, pp. 257-279). Imago. (Obra original publicada em 1931)

Freud, S. (1972). A interpretação dos sonhos. In J. Strachey (Ed.), Edição Standart Brasileira das obras psicológicas completas de Sigmund Freud (Vol. 4, pp. 11-565). Imago. (Obra original publicada em ca. 1900)

Freud, S. (1996). Sobre a psicopatologia da vida cotidiana. In Obras psicológicas completas de Sigmund Freud (Vol. 6, pp. 19-208). Imago. (Obra original publicada em 1901)

Freud, S. (1996). A dissolução do complexo de Édipo. In J. Strachey (Ed.), Edição Standart Brasileira das obras psicológicas completas de Sigmund Freud (Vol. 19, pp. 173-183). Imago. (Obra original publicada em 1924)

Lacan, J. (2008). O mito individual do neurótico, ou, a poesia e verdade na neurose.Zahar. (Obra original publicada em 1953)

Lacan, J. (2009). O seminário, livro 18: De um discurso que não fosse semblante. Zahar. (Obra original publicada em 1971)

Lacan, J. (1982). O seminário, livro 20: Mais, ainda. Zahar. (Obra original publicada em ca. 1972)

Martins, A. P. V. (2004). Visões do feminino: A medicina da mulher no século XIX e XX. Editora Fiocruz.

Mathias, M. C. (2013). Concepções psicanalíticas sobre os processos de decisão: Um estudo com magistrados [Dissertação de mestrado, Universidade de São Paulo]. Biblioteca Digital USP.

Resolução no 510, de 07 de abril de 2016. (2016). Dispõe sobre as normas aplicáveis a pesquisas em Ciências Humanas e Sociais. Diário Oficial da República Federativa do Brasil de 24 de maio de 2016.

Santos, M. L. (2002). Humanização da assistência ao parto e nascimento: Um modelo teórico [Dissertação de mestrado, Universidade Federal de Santa Catarina]. Repositório Institucional UFSC.

Tornquist, C. S. (2002). Armadilhas da nova era: Natureza e maternidade no ideário da humanização do parto. Revista Estudos Feministas, 10(2), 483-492. https://doi.org/10.1590/S0104-026X2002000200016

Turato, E. R. (2003). Tratado de metodologia da pesquisa clínico-qualitativa: Construção teórico-epistemológica, discussão comparada e aplicação nas áreas da saúde e humanas. Vozes. 
Vieira, E. M. (2002). A medicalização do corpo feminino. Editora Fiocruz.

Zalcberg, M. (2003). A relação mãe e filha. Elsevier.

Zanardo, G. L. P., Uribe, M. C., Nadal, A. H. R., \& Habigzang, L. F. (2017). Violência obstétrica no Brasil: Uma revisão narrativa. Psicologia \& Sociedade, 29. https://doi.org/10.1590/1807-0310/2017v29155043

Flávia Angelo Verceze

Professora Assistente do Departamento de Psicologia e Psicanálise da Universidade Estadual de Londrina (UEL), Londrina-SC. Brasil.

E-mail: vercezeflavia@gmail.com

(1) https://orcid.org/0000-0003-0751-383X

\section{Silvia Nogueira Cordeiro}

Docente Permanente, Adjunto B, do Departamento de Psicologia e Psicanálise e do Programa de Pós-graduação em Psicologia da Universidade Estadual de Londrina (UEL), Londrina - SC. Brasil.

E-mail: silvianc2000@gmail.com

(1) https://orcid.org/0000-0003-0834-8610

Endereço para envio de correspondência:

Universidade Estadual de Londrina, Departamento de Psicologia e Psicanálise, Centro de Ciências Biológicas, Campus Universitário. Rodovia Celso Garcia Cid (Pr 445), Km 380. CEP: 86057-970. Londrina - PR. Brasil.

Recebido $11 / 07 / 2019$

Aceito 27/10/2020

Received $07 / 11 / 2019$

Approved 10/27/2020

Recibido 11/07/2019

Aceptado 27/10/2020

Como citar:Verceze, F. A., \& Cordeiro, S. N. (2021). A decisão de uma mulher por parir naturalmente: Contribuições psicanalíticas. Psicologia: Ciência e Profissão, 41, 1-11. https://doi.org/10.1590/1982-3703003225937

How to cite:Verceze, F. A., \& Cordeiro, S. N. (2021). A woman's decision to have a natural childbirth: Psychoanalytic contributions. Psicologia: Ciência e Profissão, 41, 1-11. https://doi.org/10.1590/1982-3703003225937

Cómo citar:Verceze, F. A., \& Cordeiro, S. N. (2021). La decisión de una mujer por el parto natural: Aportes psicoanalíticos. Psicologia: Ciência e Profissão, 41, 1-11. https://doi.org/10.1590/1982-3703003225937 